\title{
Scanning electron microscopy of newly excysted juvenile and adult Cyclocoelum mutabile (Digenea)
}

\author{
D.D. Tajrine, N.N. Kapoor, and J .D. McLaughlin
}

\begin{abstract}
In this study, changes were examined in surface structures and tegumental morphology of newly excysted, migrating, and adult Cyclocoelum mutabile obtained from experimentally infected coots (Fulica americana). Newly excysted juveniles were spinous and had two large depressions situated at the anterior tip of the body and a large acetabulum. Small papillae were scattered around the mouth region and also formed a row that encircled the anterior end of the fluke. Four groups of larger papillae, two ventrolateral and two lateral, originated from points slightly posterior to the mouth region. The two ventrolateral bands of papillae terminated slightly posterior to the acetabulum; the two lateral rows of papillae terminated about three-quarters of the length along the specimen. Six large multilobed papillae were associated with the acetabulum. Juveniles migrating through the liver lost the spines and papillae by day 6 , but the anterior depressions persisted into the adult stage. The tegument of 6- and 12-day-old flukes was smooth with a varying number of transverse folds. The tegument of 15-day-old specimens from the body cavity ranged in appearance from folded and pitted to reticulate. The reticulations were more prominent in adults and the entire body was covered with a reticulate pattern of loculus-like structures that are believed to aid in the movement of the flukes within the air sacs of the coot host.
\end{abstract}

Résumé : Nous avons étudié les modifications des structures superficielles et de la morphologie tégumentaire chez des Cyclocoelum mutabile fraîchement désenkystés, des migrateurs et des adultes provenant de foulques (Fulica americana) infectées expérimentalement. Les juvéniles fraîchement désenkystés sont épineux, portent deux importantes dépressions à l'extrémité antérieure de leur corps et un acetabulum de grande taille. Ils ont de petites papilles qui sont dispersées autour de la région buccale et dont certaines forment une rangée qui encercle la partie antérieure de la douve. Quatre groupes de papilles plus grandes, deux groupes latéroventraux et deux latéraux, ont leur origine en des points situés légèrement en arrière de la région buccale. Les deux bandes latéroventrales de papilles s'insèrent un peu en arrière de l'acetabulum; les deux rangées de papilles latérales aboutissent aux trois quarts de la longueur du corps. Six grandes papilles multilobées sont associées à l'acetabulum. Les juvéniles qui migrent à travers le foie perdent leurs épines et leurs papilles avant le jour 6, mais les dépressions antérieures persistent jusqu'au stade adulte. Chez les douves de 6 à 12 jours, les téguments sont lisses et portent des replis transverses en nombres variables. Les téguments des douves de 15 jours trouvées dans la cavité corporelle sont variables: certains portent des replis et des ponctuations, d'autres sont réticulés. Les réticulations sont plus importantes chez les adultes et le corps entier est recouvert d'une réticulation formée de petites loges qui aident sans doute les douves à se déplacer dans les sacs aériens des foulques.

[Traduit par la Rédaction]

\section{Introduction}

Cyclocoelum mutabile is a large fluke that infects the air sacs of coots (Fulica americana). The flukes reach the air sacs following a 15- to 18-day migration period in the coot host. During the first $24 \mathrm{~h}$ post infection, the newly excysted juveniles migrate through the intestinal wall, enter the body cavity, and penetrate the liver capsule. Over the next 2 weeks the juveniles burrow through the liver, feeding on tissue and growing rapidly. The flukes emerge from the liver by day 15

Received October 15, 1998. Accepted April 19, 1999.

D.D. Tajrine, N.N. Kapoor, and J.D. McLaughlin. ${ }^{1}$ Department of Biology, Concordia University, 1455 de Maisonneuve Boulevard West, Montréal, QC H3G 1M8, Canada.

${ }^{1}$ Author to whom all correspondence should be addressed (e-mail: mcljd@alcor.concordia.ca). and reenter the body cavity. They migrate to the air sacs by day 18 and become ovigerous between 28 and 35 days post infection (McLaughlin 1977, 1983).

Numerous scanning electron microscopy (SEM) studies comparing the tegument and surface structures of newly excysted juveniles with those of maturing or adult flukes have shown that significant changes may occur during establishment in the final host. The most common of these involve modification of tegumental topography and modifications of the shape, structure, or distribution of body spines and sensory papillae (Hong et al. 1991). Such changes have been reported for enteric species as well as for species that migrate within the host and establish in parenteral sites. Among the species that live in parenteral sites, only the developmental stages of Schistosoma mansoni (e.g., Voge et al. 1978; Crabtree and Wilson 1980; Basch and Basch 1982) and Fasciola hepatica (e.g., Bennett 1975a, 1975b, 1975c; Koie et al. 1977) have been studied intensively, hence little is known of the changes in surface structure that occur as 
flukes migrate from one site to the next within the definitive host. As $C$. mutabile has a initial liver phase like $F$. hepatica, but occupies a different final site, it affords a opportunity to examine ontogenetic changes in surface features during migration.

This study is a continuation of work on the biology and host-parasite relations of $C$. mutabile and documents, at the SEM level, tegumental changes that occur as the flukes develop to maturity within the coot host.

\section{Materials and methods}

The coots used in this study were hatched from eggs collected in the Delta Marsh, Delta, Manitoba, Canada. They were housed in the waterfowl holding facilities at Concordia University and maintained on a diet of $17 \%$ laying mash (Nutribec, Montréal), and had unlimited access to water. Laboratory populations of Lymnaea elodes, decended from snails collected at Delta, were maintained in aquaria on a diet of romaine lettuce supplemented with Tetramin and chalk for calcium. Housing, care, and manipulation of the animals used in this study conformed to the principles and guidelines set forth by the Canadian Council on Animal Care.

Eggs collected from adult $C$. mutabile recovered from the air sacs of naturally infected coots were placed in water at $20-22^{\circ} \mathrm{C}$ and hatched within $3 \mathrm{~h}$. Snails were exposed individually in 24well tissue-culture plates. Two millilitres of aged tap water were placed in each well of four tissue-culture plates. A snail and two miracidia were added to each well and left for $12 \mathrm{~h}$. The snails were then transferred to aquaria held at $20-22^{\circ} \mathrm{C}$ and maintained on a diet of romaine lettuce as described above until metacercariae were produced.

Newly excysted juveniles were obtained by incubating metacercariae in a mixture consisting of equal parts trypsin and coot bile (by weight) diluted to $5 \%$ in Tyrode's solution at $39^{\circ} \mathrm{C}$. Twenty-five metacercariae were fed to each of eight laboratoryraised coots. The coots were necropsied at 1, 3, 6, 9, 12, 15, and 30 days post exposure following procedures described in McLaughlin (1977). Flukes were obtained from liver squashes (days 1-12), then from the body cavity (day 15), and thereafter from the air sacs.

Specimens for SEM study were rinsed thoroughly in warm $0.85 \%$ saline, cleaned following protocols described in Kapoor (1989), and fixed in $2 \%$ glutaraldehyde in phosphate buffer $(\mathrm{pH} 7.1)$ for $12 \mathrm{~h}$. Following fixation, specimens were washed in several rinses of fresh buffer, postfixed for 30-45 min in 1\% osmium tetroxide at $4^{\circ} \mathrm{C}$, and stored in $70 \%$ ethanol. Specimens were dehydrated, critical-point dried, mounted on stubs, coated with approximately $10 \mathrm{~nm}$ of gold, and examined in a Hitachi S520 SEM.

A second group of newly excysted juveniles were fixed in hot $5 \%$ formalin $(24 \mathrm{~h})$ and stored in $70 \%$ ethanol. These were stained in acetocarmine and prepared as whole mounts. Body length and the length and width of the acetabulum were measured on each specimen and on 18-day-old specimens prepared as whole mounts for a previous study (McLaughlin 1983).

\section{Results}

Newly excysted and 3-, 6-, 12-, 15- and 30-day-old flukes were examined. We had difficulty cleaning the specimens from the liver, and none of the few 1- and 9-day-old specimens examined were clean enough for critical study with the SEM.

\section{Newly excysted juveniles (Figs. 1-5)}

Newly excysted juveniles (Fig. 1) were elongated, lacked an oral sucker, and had a distinctly subterminal mouth and the acetabulum was situated between the anterior third and half of the body. The anterior end was rounded and had two large depressions at the tip (Figs. 1-4). The tegument displayed the typical "cobblestone" appearance described frequently for other flukes (Fig. 5) and had a dense covering of simple spines arranged in rows that encircled the body (Figs. 1-5). Spines covering the anterior tip were short, flattened, and scale-like (Fig. 4). In a zone situated around the level of the mouth, these spines gradually became transformed into the longer peglike spines that covered the rest of the body (Figs. 1-4) and the acetabulum (Fig. 5).

Numerous sensory papillae were present on the ventral and lateral surfaces. The majority of these were confined to the anterior half of the fluke. Small papillae lay anterior and lateral to the edge of the mouth. Other papillae lay scattered posteriorly and laterally to the mouth region (Figs. 2 and 3) and some formed a row that encircled the anterior end at the level of the mouth (Fig. 4). Four groups of papillae originating at points slightly posterior to the mouth region extended along the ventral and lateral surfaces. Two ventrolateral bands of about 18-22 large papillae extended slightly beyond the acetabulum (Figs. 1 and 2). The two lateral rows of papillae extended for almost three-quarters of the length of the fluke (Fig. 1). Six large papillae were located around the edge of the acetabulum. These were complex, lobulated structures and one of the lobes in each had a pore (Fig. 5). Except for those encircling the anterior end, few papillae were seen on the dorsal surface.

\section{Liver forms (Figs. 6-9)}

Body size increased during liver migration. Three-day-old flukes (Fig. 6) were larger than newly excysted juveniles, were spinous, and retained the anterior depressions. Papillae associated with the anterior region of the fluke were still visible, but only a few of the anterior papillae in the ventrolateral bands and lateral rows were seen. No spines or papillae were visible on 6-day-old specimens (Fig. 7) or on older specimens. The tegument of both 6- and 12-day-old specimens was smooth with a varying number of transverse furrows, depending on the degree of contraction (Figs. 8 and 9).

\section{Body-cavity and air-sac forms (Figs. 10-12)}

The tegumental surface of 15-day-old specimens that had recently entered the body cavity from the liver varied, depending on the degree of contraction, from a furrowed, pitted appearance characterized by conspicuous tegumental folds to a reticulated one (Fig. 10). The reticulate appearance was more pronounced in adults, where the entire body was covered with depressions and ridges that formed loculus-like structures which varied in size as a result of individual contraction (Fig. 11). The anterior depressions (Fig. 12) and the acetabulum, now minute compared with the rest of the body (Fig. 11), persisted in the adult fluke.

\section{Discussion}

As anticipated, the surface features of the newly excysted juveniles and the liver stages of $C$. mutabile were similar to those of juvenile $F$. hepatica, but those of the adults differed, reflecting adaptations to different final habitats. Newly excysted juvenile $C$. mutabile resembled the juveniles of many enteric flukes and those of $F$. hepatica, Fascioloides 
Figs. 1-5. A newly excysted juvenile Cyclocoelum mutabile. Fig. 1. Specimen in ventrolateral view; note the anterior depressions, acetabulum, and ventrolateral band (left arrowhead) and lateral row (right arrowhead) of papillae. Scale bar $=38 \mu \mathrm{m}$. Fig. 2 . Specimen in ventral view, showing the distribution of the ventrolateral bands of papillae. Scale bar $=25 \mu \mathrm{m}$. Fig. 3 . Enlarged anterior end of the specimen shown in Fig. 2, showing the distribution of papillae around the mouth and on the anterior ventral surface. Scale bar $=$ $12 \mu \mathrm{m}$. Fig. 4. Anterior end of the specimen in lateral view, showing the flattened spines, the transition area between these spines and the peglike spines seen on the rest of the body, and the row of papillae (arrowheads) that encircles the body. Scale bar $=8 \mu \mathrm{m}$. Fig. 5 . Ventral surface lateral and posterior to the acetabulum, showing the cobblestone tegument, orientation of the spines, and three of the six large papillae asociated with the acetabulum. Scale bar $=5 \mu \mathrm{m}$.
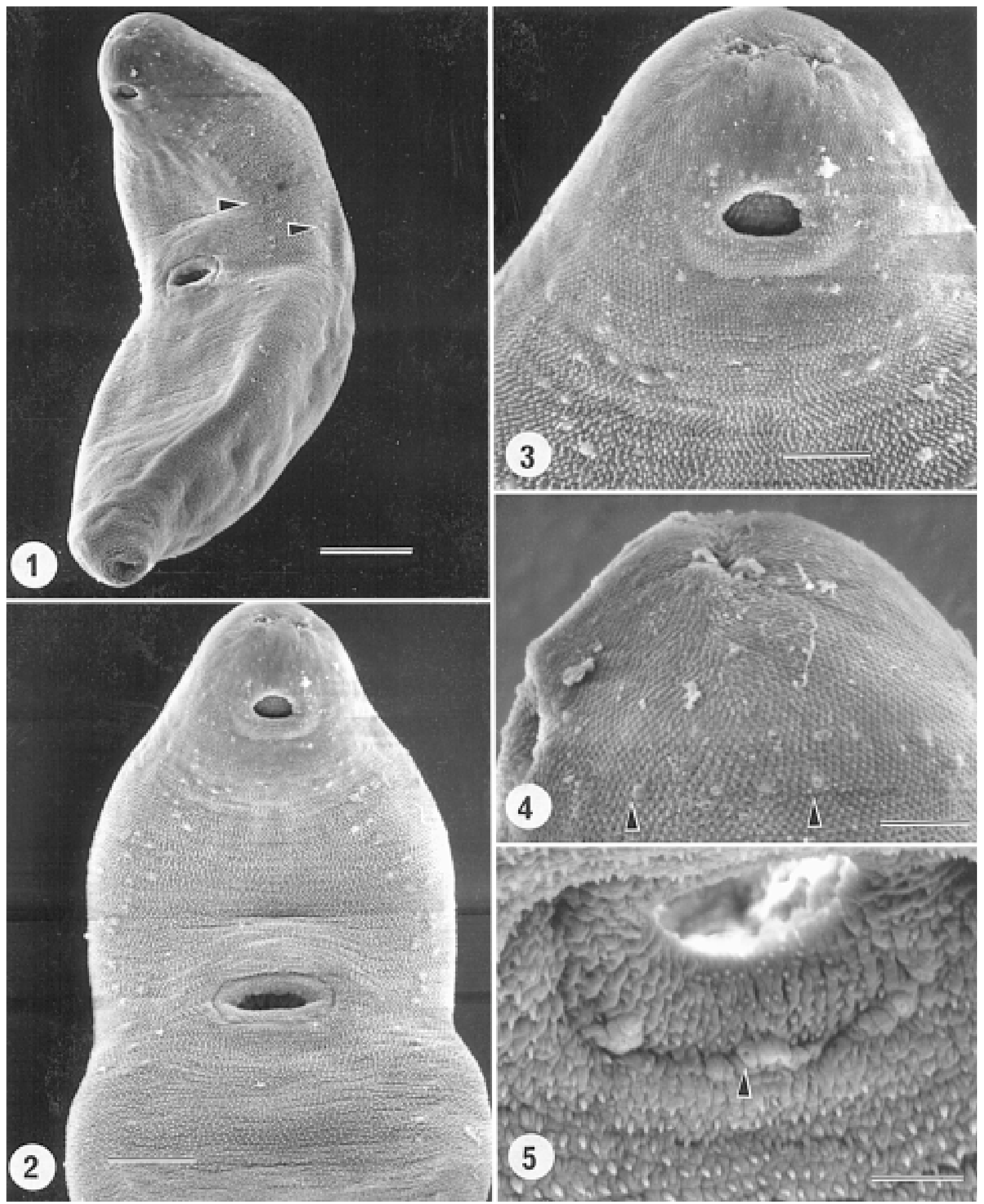

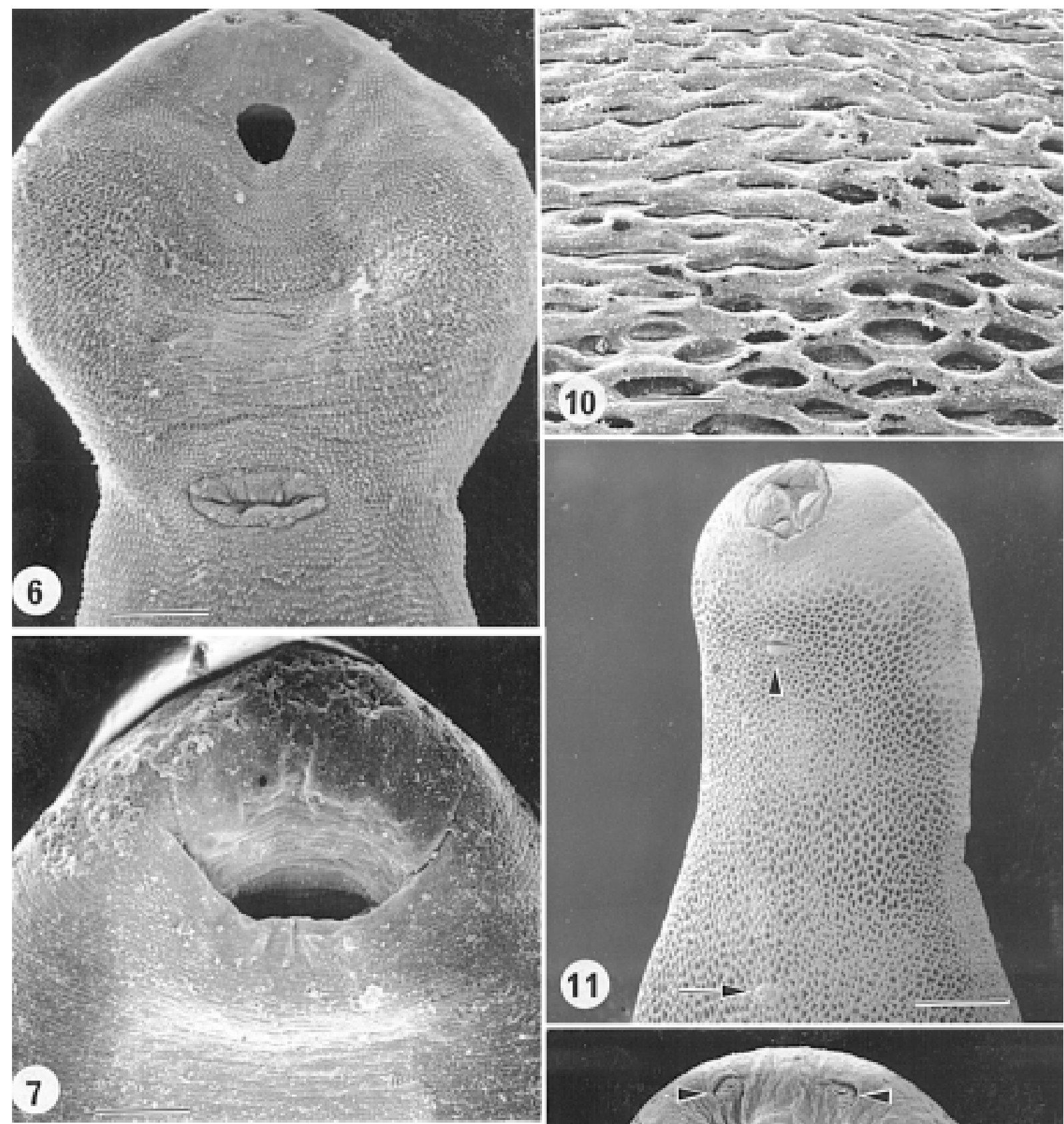

(11)
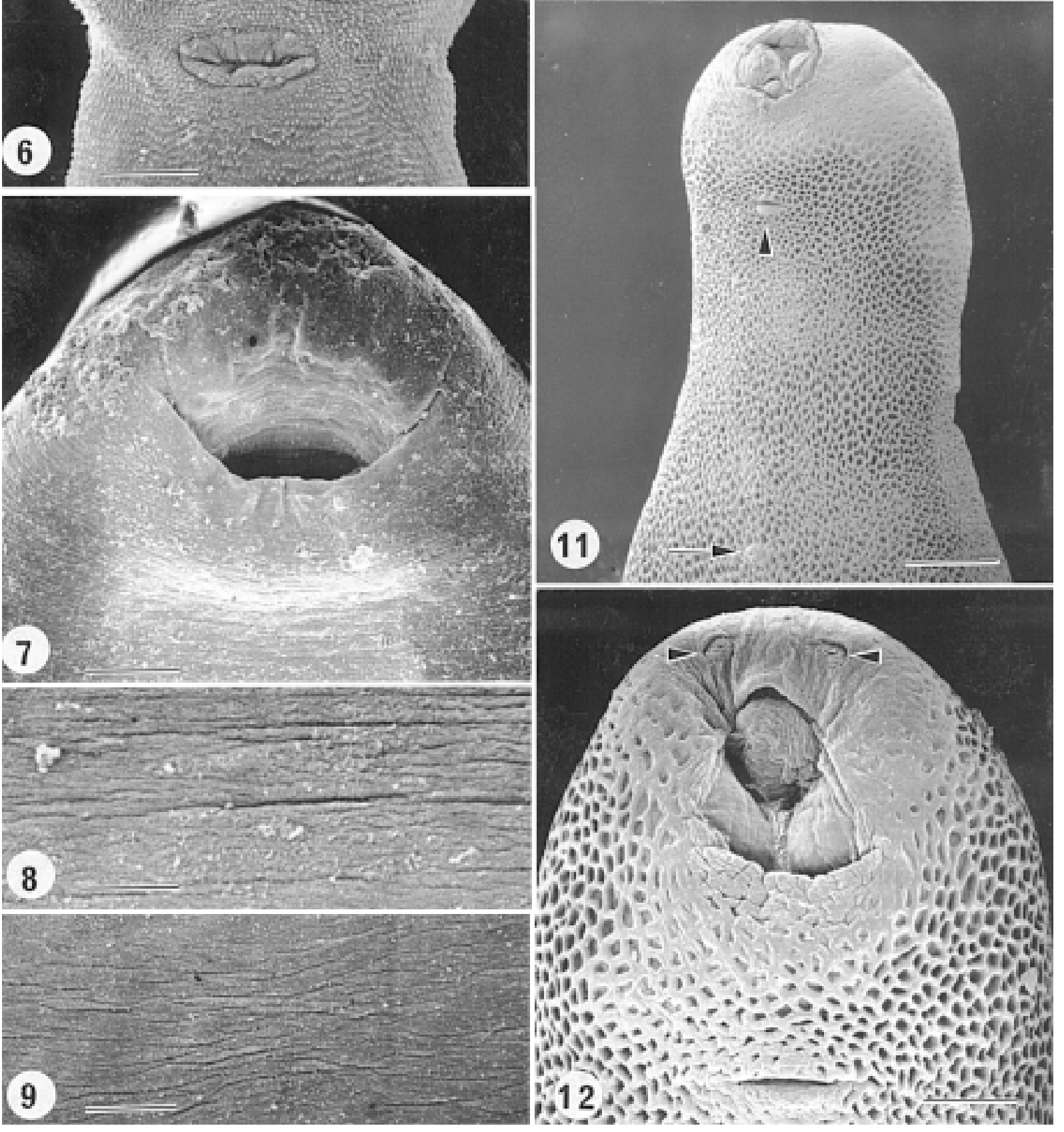
Figs. 6-12. Cyclocoelum mutabile from the liver, body cavity, and air sacs of a coot. Fig. 6. Three-day-old specimen in ventral view. Scale bar $=20 \mu \mathrm{m}$. Fig. 7. Six-day-old specimen, showing the tegument immediately posterior to the acetabulum. Scale bar $=25 \mu \mathrm{m}$. Fig. 8. The tegument immediately posterior to the acetabulum of a 6-day-old specimen. Scale bar $=8 \mu \mathrm{m}$. Fig. 9. The tegument immediately posterior to the acetabulum of a 12-day-old specimen. Scale bar $=15 \mu \mathrm{m}$. Fig. 10. The tegument of a 15-day-old specimen immediately posterior to the acetabulum. Scale bar $=25 \mu \mathrm{m}$. Fig. 11. Thirty-day-old specimen showing the reticulate tegument, genital pore (arrowhead), and acetabulum (arrow). Scale bar $=250 \mu \mathrm{m}$. Fig. 12. Thirty-day-old specimen showing the anterior depressions (arrowheads), reticulate tegument, and genital pore. Scale bar $=100 \mu \mathrm{m}$.

magna, and Paragonimus spp., which migrate to parenteral sites (Bennett 1975c; Fried et al. 1986; Higo and Ishii 1987, respectively). The most noticeable differences involved the absence of the oral sucker (a family characteristic), the type and distribution of the sensory papillae, and the presence of the anterior depressions. The papillae of newly excysted juveniles are known to vary in number, type, and distribution among genera, and as their function in digeneans remains speculative (Hong et al. 1991), it is not our intention to discuss them further. However, their unexpected disappearance by day 6 suggests that their function in $C$. mutabile is limited to the early phases of tissue migration.

The anterior depressions in $C$. mutabile are associated with two lateral tracts of ducts arising from penetration glands located in the intercaecal region in the cercarial and metacercarial stages (McLaughlin 1976). Unlike those of most digeneans, the cercariae of $C$. mutabile are not shed; they encyst as metacercariae within the first intermediate host (McLaughlin 1976). Hence, the products of the penetration glands are not used until the metacercariae excyst in the intestine of the coot host and begin penetrating the intestinal wall. In contrast, the secretions used in tissue migration by $F$. hepatica are produced by the gut epithelium (Bennett and Threadgold 1973; Bennett 1975a). The glands persist as the flukes develop in the coot (McLaughlin 1983), further suggesting that their main function is associated with tissue migration. Although the anterior depressions persist, it is unlikely that the glands remain functional once the adult flukes establish in the air sacs. No lesions or other evidence of pathology were observed in the air sacs during this study or previous studies on this fluke ( $>400$ observations on naturally or experimentally infected coots).

The peglike body spines of newly excysted $C$. mutabile are similar to those described for juvenile $F$. hepatica, $F$. magna, and Paragonimus spp. (Bennett 1975c; Fried et al. 1986; Higo and Ishii 1987, respectively). Movements of newly excysted C. mutabile in vitro and of older flukes in liver preparations are characterized by vigorous probing extensions that alternate with body contractions similar to those described for $F$. hepatica by Bennett (1975c). The flattened, scale-like spines covering the anterior tip are consistent with the probing function of this structure, which, together with secretions from the penetration glands, would disrupt tissue ahead of the fluke. The longer posterior spines would anchor the fluke in the tissue during the extension and probing phase in a manner suggested for F. hepatica (Bennett 1975c).

Adult F. hepatica, F. magna, and Paragonimus spp. retain the body spines (Yamaguti 1971; Bennett 1975a; Pariyanonda et al. 1991), albeit in altered form, whereas those on C. mutabile disappear by day 6 , before half of the liver migration is completed. In contrast to $F$. hepatica, $C$. mutabile grows rapidly during its short liver phase (McLaughlin 1983), and 6-day-old flukes are much larger than newly excysted juveniles. Six-day-old flukes may be large enough to anchor themselves in liver tissue without the aid of spines. Older flukes do not appear to require spines in order to maintain themselves in the air sacs, and spines could be a liability, causing damage to the membranes as the flukes moved over them.

Except for the loss of spines, the tegument of $C$. mutabile during liver migration appears similar to that of $F$. hepatica (Bennett 1975b; Koie et al. 1977) until just before the flukes exit, when the reticulate pattern appears. A reticulate tegument has been reported previously on metacercariae of Leucochloridiomorpha constantiae (Font and Whittrock 1980) and maturing S. mansoni (Voge et al. 1978; Crabtree and Wilson 1980; Basch and Basch 1982); however, this is a transitional morphology in each species and in neither case were the reticulations as prominent as those in C. mutabile. So far as we can determine, this is the first report of such a tegument in adult digeneans. Members of the family Cylocoelidae are parasites of the avian respiratory system, and comparative studies to determine whether the reticulate tegument is unique to species that infect the air sacs or occurs also on cyclocoelids that infect the trachea or nasal sinuses would be of interest.

The tegument of flukes forms a physiologically active interface with the host, and the increase in surface area produced by the reticulations may be of physiological significance once the flukes have entered the air sacs. However, the reticulations, or more specifically the loculus-like structures they produce, may also be important in locomotion. Flukes that have emerged from the liver are active and move using muscular extensions and contractions of the body. They can travel horizontally or vertically and can maintain their position on the air-sac membrane when inverted (a frequent observation during necropsy). Their mobility is unusual in flukes and is even more remarkable in view of the fact that they lack an oral sucker and have an acetabulum that is minute, relative to the size of the fluke, at this stage of their development. The length of newly excysted juveniles $(n=13)$ and 18-day-old flukes $(n=18)$ (selected because they are the oldest specimens in which the acetabulum can be measured accurately) is $0.45 \pm 0.03$ (mean \pm SD) and $11.5 \pm 0.08 \mathrm{~mm}$, respectively (a 25-fold difference), whereas the dimensions of the acetabulum are $55 \pm 4 \times 58 \pm 4$ and $83 \pm 8 \times 94 \pm$ $5 \mu \mathrm{m}$, respectively (less than a 2 -fold difference). The acetabulum is large enough to function effectively as an attachment structure in newly excysted juveniles, but is too small to be used for attachment and locomotion by the older flukes once they emerge from the liver.

On the other hand, the reticulate tegument forms a large surface area and has a multitude of loculus-like structures, each of which could function as an independent attachment point, enabling the fluke to move over the delicate air-sac membranes. Though they are active within air sacs, there is 
no evidence that adult flukes move between them. They are too large (up to $2 \mathrm{~cm}$ in length; Yamaguti 1971) to migrate between air sacs via the bronchi, and direct migration between air sacs would produce large perforations in the membranes of adjacent air sacs, with potentially serious consequences for the host. The adaptive value of this mobility appears to be associated with egg dispersal. The air sacs lie ventral to the lungs but the connections to the secondary bronchi are situated dorsolaterally or dorsally, depending on the air sac. The secondary bronchi are ciliated but the air-sac membranes are not (King 1966). Thus, eggs deposited in the air sacs could only reach the bronchi if they were transported by air currents. Although this is possible, it is likely that the most of the eggs would adhere to the moist air-sac membranes instead. The mobility of the flukes would permit them to move to the openings and deposit eggs directly in the bronchi. The position of the genital pore (Figs. 11 and 12 ) is such that the flukes need only insert the anterior end into the bronchal opening to deposit eggs. These could then be transported up the respiratory pathway and passed from the host.

\section{Acknowledgements}

We thank the Canadian Wildlife Service for providing the permits necessary to collect coot eggs and to raise the young coots, and the administration and staff of the Delta Waterfowl and Wetlands Research Station for logistic support. The work was supported by Operating Grant A-6979 from the Natural Sciences and Engineering Research Council of Canada to J.D.McL. and internal research funds provided by Concordia University. We thank Dr. David Crowe, University of New Brunswick, for several insightful suggestions in the development of this project.

\section{References}

Basch, P.F., and Basch, N. 1982. Schistosoma mansoni: scanning electron microscopy of schistosomula, adults and eggs grown in vitro. Parasitology, 85: 333-338.

Bennett, C.E. 1975a. Fasciola hepatica: development of cecal epithelium during migration in the mouse. Exp. Parasitol. 37: 426-441.

Bennett, C.E. 1975b. Scanning electron microscopy of Fasciola hepatica L. during growth and maturation in the mouse. J. Parasitol. 61: 892-898.

Bennett, C.E. $1975 c$. Surface features and sensory structures of newly excysted juvenile Fasciola hepatica L. J. Parasitol. 61: 886-891.
Bennett, C.E., and Threadgold, L.T. 1973. Electron microscope studies of Fasciola hepatica XIII. Fine structure of the newly excysted juvenile. Exp. Parasitol. 34: 85-99.

Crabtree, J.E., and Wilson, R.A. 1980. Schistosoma mansoni: a scanning electron microscope study of the developing schistosomulum. Parasitology, 81: 553-564.

Font, W.F., and Whittrock, D.D. 1980. Scanning electron microscopy of Leucochloridiomorpha constantiae during development from metacercaria to adult. J. Parasitol. 66: 955-964.

Fried, B., Vates, T.S., Wisnewski, N., and Stromberg, B.E. 1986. Scanning electron microscopy and chemical excystation of Fascioloides magna (Trematoda) metacercariae. Z. Parasitenkd. 72: 631-634.

Higo, H., and Ishii, Y. 1987. Comparative studies on surface ultrastructure of newly excysted metacercariae of Japanese lung flukes. Parasitol. Res. 73: 541-549.

Hong, S.J., Chai, J.Y., and Lee, S.H. 1991. Surface ultrastructure of the developmental stages of Heterophyopsis continua (Trematoda: Heterophyidae). J. Parasitol. 77: 613-620.

Kapoor, N.N. 1989. Distribution and innervation of the sensilla on the mouthparts of the carnivorous mayfly nymph Paragnetina media (Walker) (Plecoptera: Perlidae). Can. J. Zool. 67: 831-838.

King, A.S. 1966. Structural and functional aspects of the avian lungs and air sacs. In International review of general and experimental zoology. Vol. 2. Edited by W.J.L. Felds and R.J. Harrison. Academic Press, New York. pp. 171-267.

Koie, M., Nansen, P., and Christensen, N.O. 1977. Stereoscan studies of rediae, cercariae, cysts, excysted metacercariae and migratory stages of Fasciola hepatica. Z. Parasitenkd. 54: 289-297.

McLaughlin, J.D. 1976. Experimental studies on the life cycle of Cyclocoelum mutabile (Zeder) (Trematoda: Cyclocoelidae). Can. J. Zool. 54: 48-54.

McLaughlin, J.D. 1977. The migratory route of Cyclocoelum mutabile (Zeder) (Trematoda: Cyclocoelidae) in the American coot, Fulica americana. Can. J. Zool. 55: 274-279.

McLaughlin, J.D. 1983. Growth and development of Cyclocoelum mutabile (Cyclocoelidae) in coots, Fulica americana (Gm.). J. Parasitol. 69: 617-620.

Pariyanonda, S., Maleewong, W., Arunyanart, C., Kan-Lah, P., Morakote, N., and Thong-Pho-Lane, S. 1991. Scanning electron microscopy of cuticular surface of the adults Paragonimus heterotremus in Phitsanulok, Thailand. Southeast Asian J. Trop. Med. Public Health, 22: 99-101. [sic]

Voge, M., Price, Z., and Bruckner, D.A. 1978. Changes in tegumental surface during development of Schistosoma mansoni. J. Parasitol. 64: 585-592.

Yamaguti, S. 1971. Synopsis of the digenetic trematodes of vertebrates. Vol. 1. Keigaku Publishing Co., Tokyo. 